\title{
Fusion of horizons: Realizing a meaningful understanding in qualitative research
}

\author{
Kevin A. Bartley \\ Jeffrey J. Brooks
}

First Published Online at Qualitative Research by Sage journals

December 30, 2021

https://doi.org/10.1177/14687941211065164

https://journals.sagepub.com/doi/pdf/10.1177/14687941211065164

\begin{abstract}
This paper explores a case example of qualitative research that applied productive hermeneutics and the central concept, fusion of horizons. Interpretation of meaning is a fusing of the researchers' and subjects' perspectives and serves to expand understanding. The purpose is to illustrate an exemplar of qualitative research without establishing a rigid recipe of methodology. The illustration is based on in-depth observational and textual data from an applied anthropological study conducted in western Alaska with Yup'ik hunters and fishers and government agency employees as they worked towards collaborative management. The metaphor of the hermeneutical circle is showcased to help the reader understand the philosophical underpinnings and the analytical processes used to realize a meaningful interpretation. A series of organizing systems for the interpretation is described, culminating in a final organizing system to communicate a fully realized understanding of collaborative management at the time.
\end{abstract}




\section{Keywords}

Applied hermeneutics, co-construction, collaborative management, meaning units, ontology, organizing system, pre-understandings, sociocultural meanings, Yukon-Kuskokwim Delta

\section{Introduction}

This paper explores a case example of qualitative research rooted in an interpretive paradigm know as productive hermeneutics. We adapted the principles of the paradigm from Brooks (2003), Gadamer (1989), and Patterson and Williams (2002). Productive hermeneutics is a qualitative interpretive paradigm applied to understand meaning. Fusion of horizons is a central concept in Gadamer's hermeneutic ontology in which interpretation of meaning is a process of fusion of the subjects' and the researchers' understandings of concepts and categories relevant to the research (Gadamer, 1989; Lawn, 2006; Heckman, 1984; Patterson and Williams, 2002). A fusion of horizons happens whenever a research subject's viewpoints are understood in relation to what a researcher already knows about a topic based on experience and disciplinary perspective (Thompson et al., 1994).

The work of hermeneutics is clarifying the conditions that facilitate understanding rather than the development of a strict procedure for understanding (Gadamer, 1989). Listening, language, dialog, and discourse are central components in hermeneutics. 'Hermeneutics encourages not objectification but listening to one another-for example, the listening to and belonging with someone who knows how to tell a story' (Gadamer, 1994: xi). Social scientists and other scholars employ hermeneutics to interpret meanings of human behavior and 'experiences of being in the world' (Turner, 2003: 3). Our analysis draws on the paradigm of productive or applied philosophical hermeneutics (Gadamer, 1989; Grondin, 1994). 
Interpretive researchers cannot sidebar or bracket their preconceptions to truly recreate another person's experience (Gadamer, 1989). The reader of the text 'cannot separate in advance the productive prejudices that enable understanding' from those biases that lead to misinterpretation; 'rather this separation must take place in the process of understanding itself' (Gadamer, 1989: 295-296). Pre-understandings may include cultural perspectives, theories, research results, and subject matter expertise that researchers and managers share with their participants (Arnold and Fischer, 1994). Researchers coproduce meaning while generating and interpreting subjects' interview texts (Nicholson, 1984; Patterson and Williams, 2002). There is no true interpretation waiting to be discovered; the reader of the text brings previous knowledge and preconceptions about the topic into the interpretation to co-construct meaning with the participants (Brooks, 2003). Understanding comes from the interpreter as much as it comes from the interviews, and those pre-understandings are a condition and key component of understanding (Arnold and Fischer, 1994; Gadamer, 1989; Turner, 2003).

We focus on analysis, and the purpose is to illustrate an exemplar of qualitative inquiry. We are not prescribing or trying to establish a rigid recipe of methodology that leaves no room for flexibility or creativity, as understandings are not fixed and undergo continual changes and evolutions through time (Gadamer, 1989; Lawn, 2006; Mishler, 1990; Turner, 2003). This is the story of how we realized a meaningful understanding in qualitative research.

\section{Case example}

The illustration is based on an applied anthropological study we conducted in western Alaska with Yup'ik hunters and fishers and agency resource managers, who were working on and who continue to work towards collaborative management of fish and wildlife (Bartley, 2014; Brooks 
and Bartley, 2016). At the time of the study, local participation in collaborative management sponsored by the agencies was in decline due to several challenges related to cultural awareness, communication, and process. The purpose of the study was to document the challenges and offer insights and recommendations to improve collaboration, thereby defining meaningful ways for Yup'ik hunters and fishers to participate with the agencies. The primary objectives were to identify and document barriers to and enablers of participation in management, perceptions of a meaningful role, and factors contributing to declining participation.

The study used participant observation combined with extensive field notes, records of public meetings, and depth interviewing. Interviews were guided conversations and audio recorded, producing 636 pages of text about participation in management. Bartley (2014) guided the conversations based on what he had learned by participating in public management meetings. As he learned more from what the subjects shared about their involvement in the management process, he asked different questions to understand new meanings and perspectives. A dialog developed between the researcher and the subjects and between the coauthors (Supplemental Materials, Appendix A). This type of open-ended dialog is a central feature in hermeneutic philosophies of understanding (Freeman, 2006; Gadamer, 1989). Detailed results are presented elsewhere (Bartley, 2014; Bartley et al., 2014; Brooks and Bartley, 2016). To set the stage, we share what we learned during fieldwork.

\section{Participant observation}

As a nonindigenous male in his early thirties growing up outside Alaska, the primary author found himself in a quite different place from his Yup'ik informants. He had a lot to learn about life in the Delta by listening to, interacting with, and thinking about those informants who were 
imbedded in a place and reality largely foreign to him. The ethnographic field work and anthropological analyses to follow were 'an intellectual effort' best described as 'an elaborate venture in' understanding Yup'ik cultural realities through 'thick description' (Geertz, 1973: 6).

Prior to visiting communities and interviewing key informants, we observed meetings of advisory councils and working groups in 2012 (Bartley, 2014). During January through March 2013, the primary author engaged in many conversations and activities with residents of the Delta. He observed collaborative meetings and interactions between subsistence fishers, hunters, and agency managers; he hunted, trapped, collected wood, took steam in the maqivik, and visited schools with his Yup'ik counterparts. He spent hours travelling by snow machine on the land and airplane over the land. Being in the Yup'ik world, one is always preparing for some activity and moving on the land and waters or preparing to move (Barker, 1993).

While we listened to and read transcripts of the meeting of the Kuskokwim working group on June 20, 2012, we became aware of several cultural, political, and procedural factors we thought may substantially affect the outcomes of local participation in fisheries management. From the moment the meeting began, there was an air of frustration.

We are missing the tribal government. Desperation is here. Greed sets in, and it hits the fishing hard ... Its time to give some of those [harvest] closures a lift immediately! We are trying very hard to live with the four inch [net] mesh ... People are frustrated (Journal Notes, June 20, 2012).

Although some tempers flared during the first two hours, a plea for cooperation and compromise was continuously repeated by subsistence harvesters living in various communities along the Kuskokwim River. 
My heart bleeds. People don't say a lot, but they feel a lot. People are saying they need fish. [Offshore commercial] Pollock [fishing] is impacting the Kuskokwim. [I] hope there is some management plan for the people (Journal Notes, June 20, 2012).

We observed several things affecting collaboration, including challenges related to styles of speech, levels of comprehension, and flow of information between stakeholders. Language differences and the need for translation often presented challenges, and the Yup'ik language plays a role in the identity politics of the people and their social interactions with agencies. The primary author learned and spoke some words in the indigenous language to build trust and rapport. He also observed differences in how groups talked about fish and wildlife issues and problems related to how information was shared; when, where, and how often meetings were held; and timing of stakeholders' involvement.

People have stopped fishing. The process is the problem. The information is not getting to us. I get the feeling that this is being jammed down our throats (Journal Notes, September 27, 2012).

We observed larger political, economic, and social factors affecting participation of subsistence harvesters. For example, on the Yukon River where Chinook (king) salmon escapement has been a concern, subsistence harvesters have become increasingly distraught over management of the species. At meetings of the Yukon River Association, we heard people describe detrimental impacts of the commercial Pollock fishery on king salmon runs bound for the watersheds of western Alaska.

There is no one wasting fish on the river. All the waste is happening out on the sea. No matter what you do on the river the fish are not gonna come back. You can 
restrict everybody on the river and ... get no results until you put your foot down on

those trawlers [high seas, Pollock fishing vessels] (Journal Notes, August 14, 2012).

In response, the Yukon association coordinator asked for the discussion to remain only focused on in-river management issues. In reply, the resident of the lower Yukon stated:

That's a problem during this meeting. We are always cut off. We don't matter. Out there [on the high seas] there's no control. Maybe you can wait till they go extinct till you do something (Journal Notes, August 14, 2012).

Subsistence harvesters cannot understand agency managers' reluctance to talk about off-shore commercial fisheries. For subsistence harvesters, salmon recognize no jurisdictional boundaries such as those ascribed and placed on salmon by agency managers and scientists. In the eyes of subsistence harvesters, caring for salmon should include discussing and acting on issues that affect salmon while they are in the ocean as well as in rivers.

We observed many people express the importance of being able to practice their way of life and continue to engage in what they had been taught to do by their elders. Being able to continue one's way of life requires that there be opportunities to practice elements of one's cultural identity and spirituality. King salmon declines in recent years, for example, have called into question whether those opportunities will continue. What is at stake for the Yup'ik is the ability to continue to teach their children to hunt, fish, and continue a way of life. To do so, they must play a meaningful role in decision making.

\section{Productive hermeneutics}

To understand how to improve collaborative management in western Alaska, we needed to gain an in-depth understanding of the many interrelated parts of the process used by the agencies to 
manage fish and wildlife. We needed to continuously re-examine each of the interview transcripts and observations recorded in field notes and at management meetings to understand the parts of collaboration. Our task was to get closer to a fully realized understanding of all the ways the details of the process related to one another and to collaborative management. To do it, we applied principles from productive hermeneutics (Gadamer, 1989).

As part of the analysis, it is essential for researchers to clearly communicate their preunderstandings of the phenomenon and assumptions about social science. This is done in part by choosing a research paradigm that adheres to a certain set of congruent normative commitments and philosophical assumptions used to define, delimit, and guide one's approach to social science (Patterson and Williams, 1998). Research goals (axiology), philosophical assumptions about reality and human nature (ontology), and how researchers choose to study reality and the nature and limits of knowledge (epistemology) must be aligned (Patterson and Williams, 1998). In any study design, the research assumptions and principles must be coherent and internally consistent (Brooks, 2003; Carr, 2010; Patterson and Williams, 2002, 2005). Our goal was to understand complex sociocultural relations, and our assumptions about reality lean towards a pluralist understanding that multiple realities exist. Accordingly, we would be misguided if we chose a hypothetico-deductive approach, based in positivism, in which the research goal is prediction and control of human behavior, and where there is a single reality or truth to be evidenced.

Researching collaborative resource management where the collaborators are from two or more distinct cultures requires understanding complex sociocultural meanings. Positivistic paradigms are not appropriate for understanding complex social and cultural issues in which the definition of the problem exists in the eyes of the beholders, in this case, the collaborators (Allen 
and Gould, 1986; Brooks and Champ, 2006; Patterson and Williams, 2002). Foundational hypothesis testing and multivariate statistical reasoning could help researchers and managers identify variables affecting participation levels, but these approaches would not be useful for understanding how participants define and interpret their roles in collaboration or serving on advisory boards. Because the primary objective was to understand the collaborators' cultural orientations and ways of knowing about land, animals, and management, it was appropriate to apply an interpretive approach based in productive hermeneutics and fusion of horizons. In the context of cross-cultural understanding, 'one of the virtues of the fusion of horizons is the possibility of extending one's own cultural horizon to embrace and interact with one wholly alien and remote from one's own' (Lawn, 2006: 122).

Productive hermeneutics has been applied by social scientists to study sociocultural perspectives related to environmental management (Brooks et al., 2006; Carr, 2010; Patterson et al., 1998; Patterson and Williams, 2002). We worked within a narrative ontology in which we believe understanding human meanings and lived experiences is equivalent to listening to and interpreting stories (Gadamer, 1989; Olson, 1986; Patterson and Williams, 2002). The work of interpreting stories or texts raises the question: Can researchers separate their pre-understandings from what research subjects intend to demonstrate in their interviews? Some social scientists proposed that the researcher could gain understanding of what the original creator of a text meant or experienced through divination or reenactment (Nicholson, 1984). Some qualitative analysts assume researchers can and should attempt to bracket or separate their preconceptions from what was observed (Tufford and Newman, 2012); the objective being to recreate the experiences by empathizing with subjects (Russell, 1988; Stewart, 1983; Wertz, 1983). Productive 
hermeneutics and fusion of horizons assumes researchers are unable to bracket their preunderstandings and truly empathize with or recreate subjects' experiences (Gadamer, 1989).

The concept of fusion of horizons is key for Gadamer's hermeneutics because it describes the activity of understanding (Lawn, 2006: 149).

Each individual occupies a horizon and in attempting to understand another thing or person or text they extend their own horizon to embrace and 'fuse' with that of another. The image of fusing suggests that horizons come together, and that understanding is seen to be more of a question of (negotiated) agreement than the simple one-to-one relationship of a knowing subject to a known object.

Under this paradigm, we assume analysts, including their prior knowledge and preconceptions (horizons), play an active role in creating the interpretation (Bartley, 2014; Nicholson, 1984; Patterson and Williams, 2002). An understanding of meaning and experience is co-produced by the researchers and subjects in a fusion of perspectives; 'in cross-cultural research, however, this shared background of meanings may take considerable time and effort to develop' (Thompson et al., 1994: 434).

Pre-understanding implies that 'we understand in terms of what we already know' (Packer and Addison, 1989: 34). Patterson and Williams (2002: 100) suggested researchers 'approach a phenomenon with a preliminary understanding shaped by expectations, lifestyles, and culture which cannot be set aside in an interpretive analysis'. We suggest that a pre-understanding of a research topic is the combined product of researchers' personal histories, sets of life experiences, and cultural traditions (Thompson et al., 1994). Other sources of pre-understandings may include experience and knowledge gained while conducting research such as participant observation and interviews. Social scientists' pre-understandings guide their research 
assumptions, what questions they ask, how they design research, and what methodologies and analytical tools they choose. For example, Bartley (2014) began to understand how to develop research objectives and design the study after many months spent observing management meetings. The authors' life experiences, including educational and professional backgrounds, and their observations of and conversations with advisory board members shaped their preunderstandings of collaboration.

In the analytical process outlined below, we applied the metaphor of the hermeneutical circle to compare, continuously and simultaneously, the meaning of the parts of the qualitative data to the whole phenomenon and in turn, the whole to the parts (Brooks, 2003; Gadamer, 1989; Thompson et al., 1994). Drawing on the literature, Brooks (2003: 58) described the process. According to Geertz (1983: 69) the interpretive researcher must attempt to become engaged in a process described as 'a continuous dialectical tacking between the most local of local detail and the most global of global structure in such a way as to bring them into simultaneous view.' This process or 'intellectual perpetual motion,' describes the hermeneutic circle, which seeks no final ending point. Rather, the circle can be metaphorically thought of as spiraling outward to centrifugally encompass an ever-increasing understanding of meaning and expanded verification of the phenomenon (Gadamer, 1989; Geertz, 1983; Hirschman, 1986). This 'circle of whole and part is not dissolved in perfect understanding but ... is most fully realized' (Gadamer, 1989: 293).

The whole is collaborative management, and the parts are emerging ideas, meanings, and realizations developed through numerous observations and readings of the qualitative data. The authors closely examined the interrelationships among the parts while at the same time 
comparing those interrelationships with their overall understanding of collaborative management. The initial step was to repeatedly read whole transcripts to gain an understanding of the data in its entirety (Patterson and Williams, 2002). This global understanding was then used as the basis for a closer examination of the parts (Gadamer, 1989; Kvale, 1983; Thompson et al., 1994). Our understandings of the parts of collaborative management changed as we began to see how meanings aggregated across transcripts.

\section{Organizing system}

We produced a series of organizing systems. Hermeneutic analysis centers around the development of an organizing system Tesch (1990). The purpose of an organizing system is to provide a heuristic useful for understanding. It facilitates a meaningfully arrangement of qualitative data and helps an analyst realize and communicate understanding. The process of developing an organizing system or a set of systems plays an important role in the analysis. The final organizing system represents an understanding of the phenomenon at its most fully realized state during an analysis. We chose an organizing system based on our pre-understandings, and we developed a series of organizing systems using the hermeneutical circle. The final organizing system is a product of the interpretation and illustrates for the reader our most fully realized understanding of collaborative management at the time.

Following extensive reading, participant observation, and discussions between coauthors, Bartley (2014) adapted an a priori model to guide the qualitative interpretation toward a comprehensive understanding of collaborative management [Figure 1]. An a priori model is based on a researcher's pre-understandings of a phenomenon or issue prior to beginning new research (Brooks, 2003). Based on our extensive observations of how agency managers and 
Yup'ik hunters and fishers interacted at management meetings, we thought that differences in cultural understandings and worldviews were leading to miscommunications and unsatisfactory collaborations. We believed the managers were missing what the hunters and fishers were telling them because they were unaware of and could not see the cultural roots of the Yup'ik point of view about land and animals.

Based on what we thought at the time, we chose a model commonly referred to as the iceberg model of culture to frame the initial analyses (Hall, 1976). In the iceberg model, only a small portion of culture is visible above the waterline to those outside that culture interested in learning more about it. Hall (1976) argued that one must actively participate in or engage with a culture to understand it. We believed that we needed to identify cultural factors associated with collaborative management to understand why Yup'ik hunters' and fishers' participation in collaborative management was declining. Then, we thought it would be important to learn if and how these factors were connected to each other, and more visible outcomes of collaborative management above the waterline. 


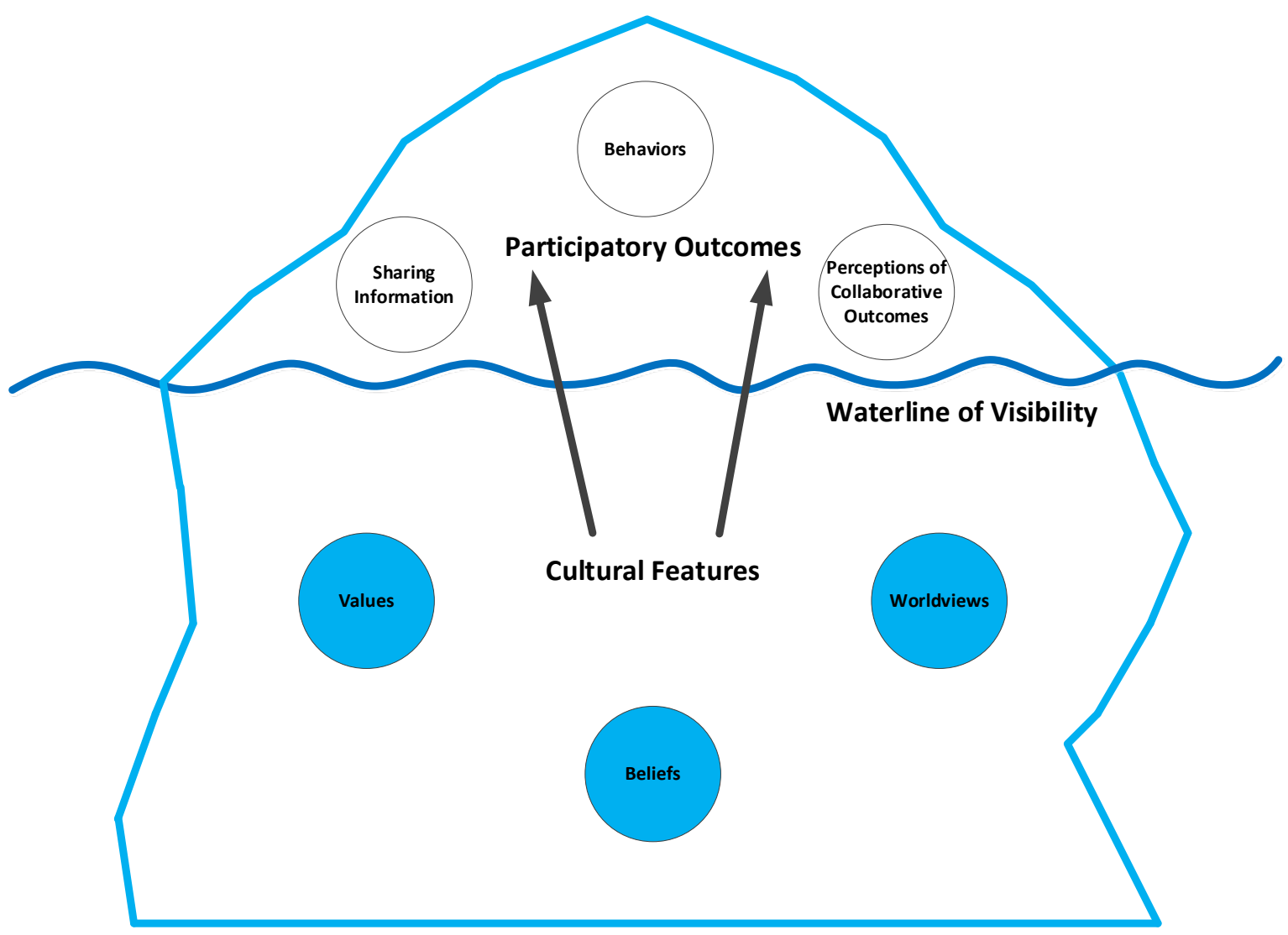

Figure 1. An a priori model based on the iceberg model of culture was adapted for the initial organizing system (Bartley, 2014; Bartley et al., 2014; Hall, 1976).

Figure 1 illustrates our pre-understandings of collaborative management influenced by our experiences observing management meetings and working as applied social scientists in rural Alaska. Our pre-understandings and the iceberg model guided us to several key preconceptions used to organize the interpretation:

1. Often unseen and unrecognized features of Yup'ik culture are located below the waterline of visibility.

2. Unseen features are closely related to Yup'ik values and beliefs and their collective worldview and epistemology.

3. Unseen cultural features are fluid and connected. 
4. Unseen cultural features are linked to and influence the visible outcomes of collaborative management above the waterline.

\section{Within transcript analysis}

We first sought an understanding of individual transcripts. Bartley (2014) began reading each transcript multiple times. He identified in each one what Patterson and Williams (2002: 103) called 'meaning units' defined as the smallest units of a text that are comprehensible on their own (Altman and Rogoff, 1987; Tesch, 1990). Meaning units typically were groups of sentences or paragraphs; these are the parts we examined in Gadamer's (1989) hermeneutical circle. Using track changes in Microsoft Word, Bartley (2014) highlighted over 1,750 meaning units in the transcripts. Concise and descriptive statements summarizing meaning units were drafted in comment tabs. Notes and memos describing what we were learning were recorded inside comment tabs. Bartley (2014) copied the meaning units into twenty-one separate files, one for each transcript, to create an understanding of each text.

Using several iterations, Bartley (2014) created a series of synopses for each text, consisting of observations and paraphrases from transcripts. For the initial round of synopses, he ordered meaning units in sequence of occurrence. He then read the first iteration of each synopsis in sequence. Commonalities began to emerge as understanding aggregated across individuals. This started to influence our thinking on collaborative management. He made a critical decision at the start of the second iteration to shift from a within transcript analysis to an across transcript analysis. He also increased dialog with his coauthors to share what he was learning and ask questions about how to address details and nuances in the analytical process. 


\section{Synopses iterations}

Seven total synopses iterations were written. Each of the six synopses iterations following the first iteration represented a single hermeneutic cycling of meaning units into emergent themes. A hermeneutic cycle is a single reading of all meaning units in each transcript, resulting in the reorganization and transformation of meaning units into themes. Themes are not static variables but compilations of meaning units or groups of details within a single transcript. When we realized commonalities in the details, we grouped them based on how we thought they related to the whole of collaborative management. We also thought about how the groupings compared to our preconceived heuristic, the iceberg model of culture. Based on discussions between members of the research team, Bartley (2014) organized meaning units and themes in the second synopses iteration according to the study objectives: barriers to and enablers of participation, meaningful role, and factors contributing to declining participation in collaborative management.

While we understood some meaning units to be relevant to the research objectives, it was not yet clear how other meaning units related to these aspects of collaborative management. Meaning units that did not clearly relate to the study objectives were later re-organized in subsequent synopses iterations into themes related to unseen cultural features below the waterline [Figure 1]. A clearer picture of collaborative management was realized when we began to better understand unseen cultural features. We began to understand our research objectives were indicators of more visible outcomes and behaviors above the waterline.

We continued to observe and organize new themes under subtitles relating to research objectives and unseen cultural features in the next three hermeneutic cycles, resulting in new synopses iterations. After the fourth revision of the interview synopses, we began to observe that three of the themes were conspicuously common across interviews and were related to culture. 
These included Yup'ik cultural features, worldviews about land and animals, and approaches to management; these aspects were interrelated and linked to barriers and enablers of meaningful collaboration. Figure 2 represents an interim organizing system for the analysis at the point of the fourth synopses iteration; it includes our growing awareness of the importance of culture, worldview, and management approach.

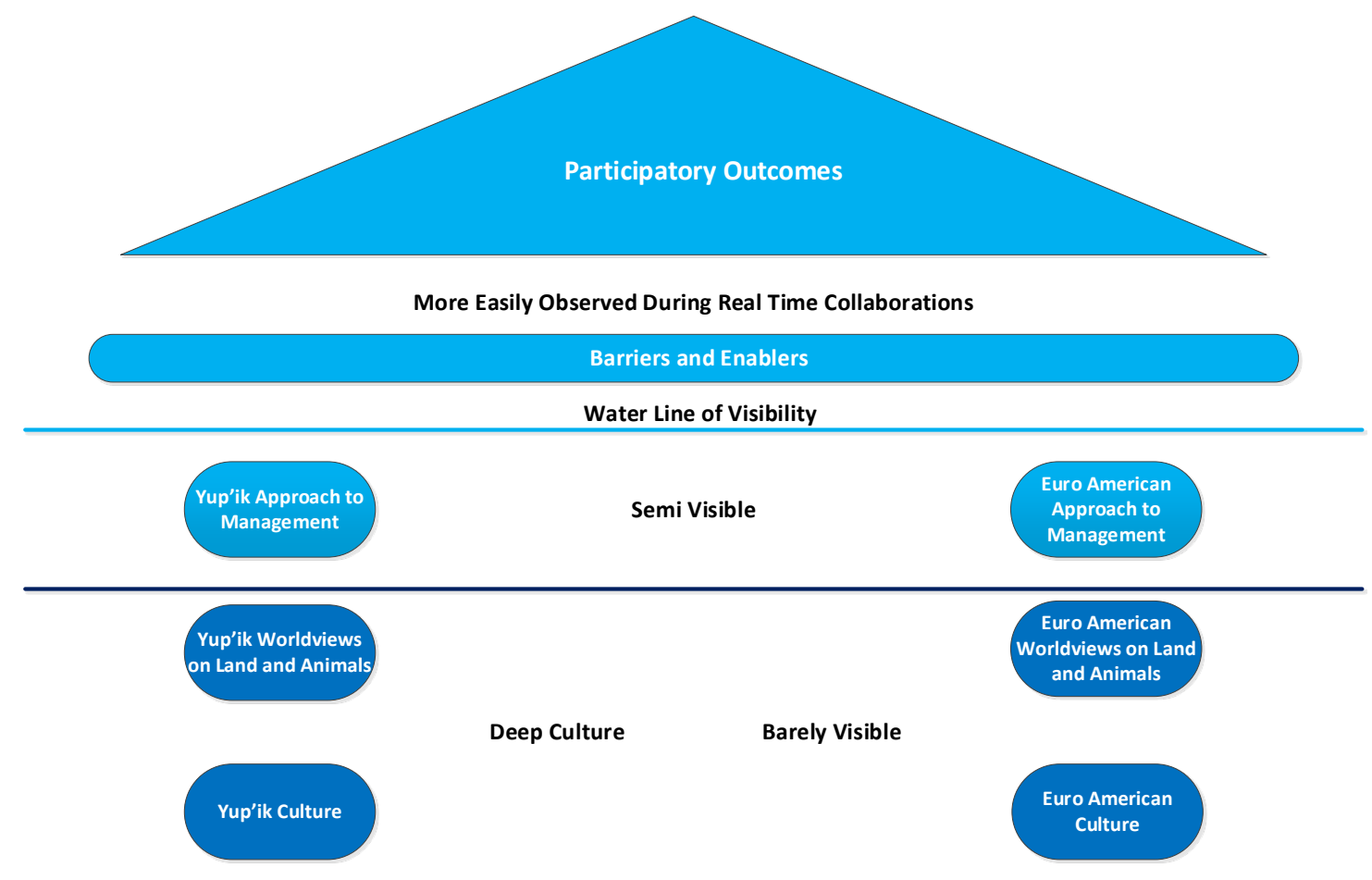

Figure 2. Interim organizing system at the time of the fourth synopses iteration (Bartley, 2014;

Bartley et al., 2014).

\section{Interrelationships}

Bartley (2014) developed a coding framework to better capture patterns in the data and linkages among meaning units and dimensions, using ATLAS.ti, a qualitative analysis software program. Seventy-two coding labels were created, using all dimensions contained in the seventh synopses iteration [Supplemental Materials, Appendix B]. He located and applied coding labels in 
ATLAS.ti to each of the meaning units highlighted in the transcripts. Various output data files were created using the software after the transcripts were labeled. One output file included a cooccurrence chart. This file identified all co-occurrences among individual labels, citing a reference number for each meaning unit with co-occurrences. The co-occurrence chart represents an empirical tool used to locate relationships among groups of meaning units. This tool was important for positioning and illustrating linkages among features in the final organizing system.

We began drawing a schematic model guided by the observable interrelations in the cooccurrence chart to illustrate numerous and detailed parts of collaborative management. At this point, we understood that some coding labels represented unseen cultural features linked to collaborative management and placed them below the waterline in the iceberg model. We positioned other coding labels above the waterline. Some coding labels were then removed, and others combined into what became features in the final organizing system. The notes and memos written in phase one guided these analytical decisions. They represented our understanding of why meaning units were interrelated. Features represent key parts of collaborative management and were created by lumping similarly related emergent themes from the across transcript analysis. We created dimensions to illustrate subcomponents of larger more complex features [Table 1]. 
Table 1. Features, dimensions, and definitions (Bartley, 2014).

\begin{tabular}{|c|c|c|}
\hline Feature & Dimension & Definition \\
\hline \multirow[t]{12}{*}{ Yup'ik Culture } & Becoming a & Cultural importance placed on listening, observing, and doing to become \\
\hline & Knowledgeable Person & knowledgeable \\
\hline & Caring and Respect & Cultural importance placed on acts of reverence that cement the reciprocal and \\
\hline & & spiritual relationships among humans, animals, and the land \\
\hline & Sharing & Cultural importance placed on sharing resources and knowledge \\
\hline & How We Talk & Culturally appropriate ways to speak and communicate \\
\hline & Respect for Elders & Cultural importance placed on respecting knowledgeable teachers, advisors, and \\
\hline & & elders \\
\hline & Familial and Communal & Cultural importance placed on maintaining close relationships among family and \\
\hline & Bonds & community members and working together \\
\hline & Who is a Real Person & Cultural perceptions of what it means to be a genuine human being and live a \\
\hline & & meaningful life \\
\hline Euro-American & Appropriate Ways to & Culturally appropriate ways for agency employees to speak and communicate \\
\hline Culture & Communicate & \\
\hline
\end{tabular}




\begin{tabular}{|c|c|c|}
\hline Feature & Dimension & Definition \\
\hline & $\begin{array}{l}\text { How One's Knowledge } \\
\text { is Measured }\end{array}$ & Culturally appropriate ways for evaluating the legitimacy of knowledge \\
\hline & Individualism & Cultural importance placed on independent tasking \\
\hline & Property & Culturally influenced perceptions regarding ownership of property \\
\hline \multirow[t]{5}{*}{ Communication } & Language Differences & $\begin{array}{l}\text { Barriers to and enablers of collaboration, stemming from language differences } \\
\text { between Yup'ik fishers and hunters and agency managers }\end{array}$ \\
\hline & Technical Jargon & $\begin{array}{l}\text { Barriers to and enablers of hunters' and fishers' meaningful role related to } \\
\text { agency managers' use of technical and scientific jargon }\end{array}$ \\
\hline & Flow of Information & $\begin{array}{l}\text { Barriers to and enablers of collaborators' meaningful role related to sharing } \\
\text { information }\end{array}$ \\
\hline & Value of Hunters' and & Barriers to and enablers of hunters' and fishers' meaningful roles related to their \\
\hline & Fishers' Knowledge & perceptions of the importance agency managers place on their knowledge \\
\hline \multirow[t]{2}{*}{ Interaction } & Working Together in & Barriers to and enablers of collaborators' relationships and collaborations in \\
\hline & Communities & remote communities \\
\hline
\end{tabular}




\begin{tabular}{|c|c|c|}
\hline Feature & Dimension & Definition \\
\hline & Working Together at & Barriers to and enablers of collaborators' meaningful roles related to \\
\hline & Meetings & collaborations at meetings \\
\hline & Cultural Awareness & Barriers to and enablers of collaborators' meaningful roles, stemming from \\
\hline & & observed levels of cultural awareness and respect \\
\hline \multirow[t]{5}{*}{ Process } & Timing & Barriers to and enablers of collaborators' meaningful roles related to the timing \\
\hline & & of involvement in collaborative management \\
\hline & Where and How & Barriers to and enablers of collaborators' meaningful roles regarding choice of \\
\hline & Collaboration Occurs & organizational framework for collaboration and how those frameworks are \\
\hline & & designed to operate \\
\hline
\end{tabular}


Figure 3 illustrates the hermeneutical relationships among meaning units, coding labels, features, and dimensions. Figure 3 also illustrates the analytical process used for the acrosstranscript analysis. The analyst conducted multiple hermeneutic cycles for each transcript, resulting in seven synopses iterations. The seventh iteration marked the final re-organization of meaning units into emergent themes.

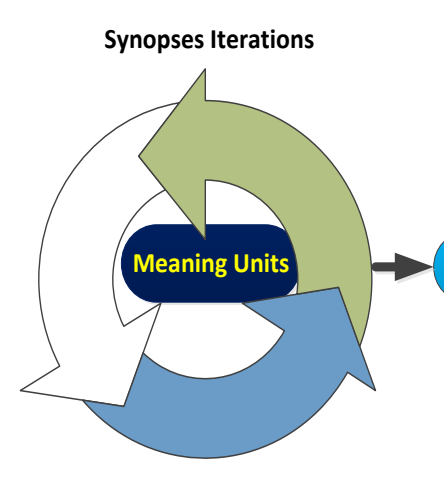

Hermeneutic Cycle(s)

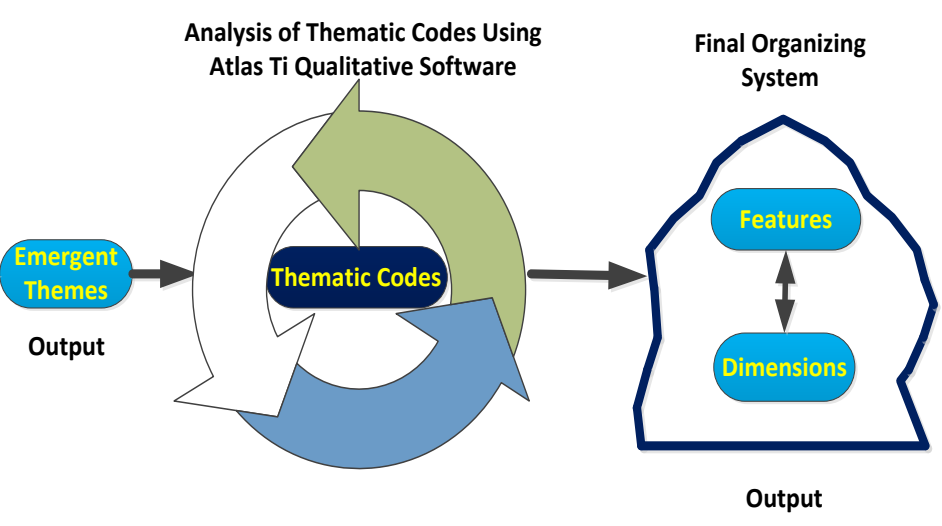

Hermeneutic Cycle(s)

Figure 3. A process for understanding meaning (Bartley, 2014; Bartley et al., 2014; Brooks and Bartley, 2016).

Some output files created in ATLAS.ti contained all meaning units from all transcripts associated with each coding label. These files allowed the analysts to quickly understand the totalities of each emergent theme. The totality of an emergent theme could be understood as its limits specified by the meaning units observed in the data. The co-occurrence chart allowed us to compare what we had learned through participant observation and the synopses iterations with a printout of all linkages and interrelationships among coding labels. Together, these tools led to the final organizing system for this analysis [Figure 4]. 


\section{Final organizing system}

Figure 4 illustrates our understanding of collaborative management in relation to our preconceived iceberg model. It represents an understanding of collaborative management at its most fully realized point in our analysis (Gadamer, 1989). The final organizing system also provides a visual aid to illustrate the interpretation and help the reader understand study findings.

We observed several important interrelationships and linkages among features and dimensions of collaborative management in the Delta. The dashed blue lines in Figure 4 show these linkages. We found special meaning units in the data that indicate and illustrate the important interrelationships. These are driving forces that penetrate through multiple levels of cultural visibility, linking unseen features at lower levels to more visible collaborative outcomes near the tip of the iceberg. The cultural features and dimensions located in levels one and two in Figure 4 often go unrecognized by agency managers. This is a problem because they drive outcomes we see and hear in real time at levels five and six. Red lines in Figure 4 show the influential forces. The outcomes at the top of the iceberg include communication failures, negative perceptions of the process, and declining participation, similar to what we observed during participant observation (Brooks and Bartley, 2016). 


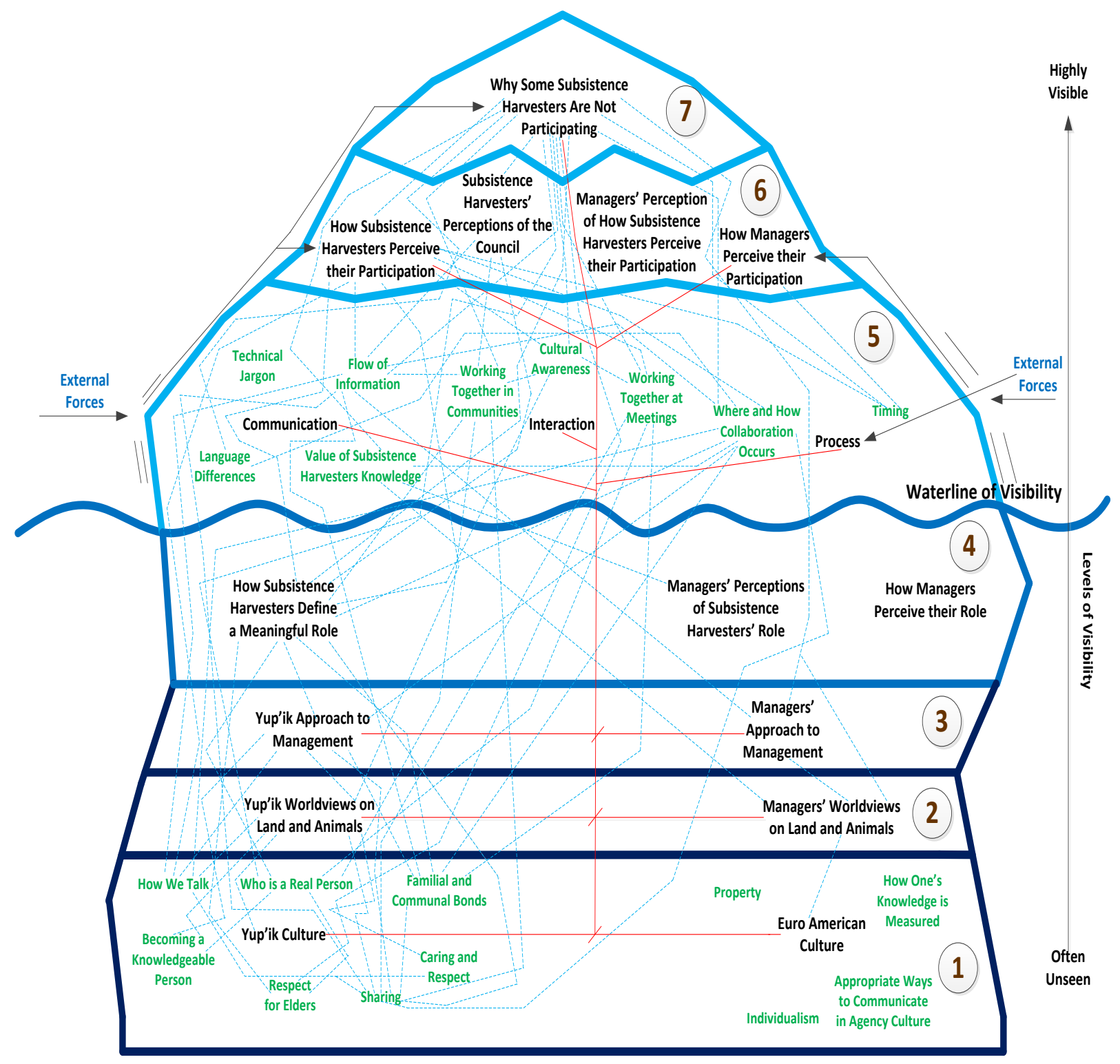

\begin{tabular}{|l|l|}
\hline $1-7$ & Levels of visibility \\
\hline Black Font & Features \\
\hline Green Font & Dimensions \\
\hline---\begin{tabular}{l} 
Empirical interrelationships/linkages \\
\hline$\longrightarrow$
\end{tabular} & $\begin{array}{l}\text { Driving forces originating from cultural } \\
\text { differences }\end{array}$ \\
\hline Council & $\begin{array}{l}\text { External forces (outside social, political, } \\
\text { economic influences) }\end{array}$ \\
\hline $\begin{array}{l}\text { Yukon Kuskokwim Delta Regional Advisory } \\
\text { Council (advisory board) }\end{array}$ \\
\hline
\end{tabular}

Note: Subsistence harvesters are Yup'ik hunters and fishers. 
Figure 4. The final organizing system is the product of the interpretation and illustrates the realization of a meaningful understanding of collaborative management in western Alaska (Bartley, 2014).

\section{Key Insights}

To effectively understand collaboration, researchers, agency managers, and local partners are required to consider how multiple features and dimensions relate to each other [Figure 4]. This requires embracing the features of culture most closely connected to the dynamics and outcomes of collaborative management [Table 1]. It also requires agency managers and their Yup'ik partners to become more aware and respectful of their differing cultures and worldviews regarding fish and wildlife and resources management.

For most Yup'ik, it is considered culturally appropriate to speak in a positive manner and only about what one knows to be true, what one has seen, heard, and experienced [Supplemental Materials, Appendix A, Table A3]. Subsistence harvesters said it is important to speak clearly using definitive statements and avoid speaking in uncertain terms [Table A3-2; 3-3]. 'How we talk' is a dimension in level one [Figure 4]. Many biologists in natural resources management apply rational, positivistic paradigms of science and generally believe truth exists. Natural resource scientists strive to obtain the one true answer or solution through replicable hypothesis testing based in statistical probability. However, because this approach to science and knowledge involves sampling errors, biases, data gaps, and other uncertainties, scientists and scientifically-trained managers often use what Yup'ik people call 'guess words' to communicate research results. This may often be the case at collaborative management meetings when biologists talk about population estimates, predictions, forecasts, trends, or statistics. Sometimes 
they speak in uncertain terms. This may often be interpreted by their Yup'ik partners as a problem because it appears as though scientists and managers do not know the true answers. The sentiment is the scientists should not be speaking about what they do not know for certain. These differences in styles of speech and beliefs about knowledge lead to misconceptions, confusion, and decreased satisfaction with the management process for all stakeholders. This problem is rooted in different worldviews and cultural norms that guide how people speak (Bartley, 2014).

Speaking negatively about [Table A17-3] or interacting inappropriately with the land, animals, or other natural resources [Table A6-6] has the power to create negative and unintended consequences for the resources, other beings, and the land. The Yup'ik believe they are connected to the land and other living beings in a reciprocal relationship [Table A6]. Although highly knowledgeable, many Yup'ik people tend not to perceive themselves to have the ability and authority to manage and control other living beings in their world; it would be disrespectful to think or act as if they did. The land has the capacity to punish actions of disrespect [Table A6$5 ; 6-6]$.

The land is - that's the law. You either follow it, follow what you're supposed to do, or you're going to get in trouble- - life and death trouble. There's no badge ... The land does not need a badge.

Many biologists and agency managers understand their roles as managing animals for the purposes of biological diversity, optimal escapement, and maximum sustained yield [Table A8]. In this role, managers possess the ability and authority to regulate, manipulate, and control resources and outcomes. Agency managers' approaches to fish and wildlife management are based in their agency's culture and their worldview. In North America, agency culture and 
worldview for most land management agencies has been substantially influenced and directed by the North American Model of Wildlife Conservation in which agency managers adhere to tenets, including 'harvest of wildlife is reserved for the noncommercial use of individual hunters' and harvest 'is to be managed in such a way that wildlife populations will be sustained at optimal levels forever' (Mahoney et al. 2008: 9).

Land management agencies manage fish and wildlife according to laws, policies, and regulations. In the Alaskan context, much policy guidance and regulatory direction come from the Alaska National Interests Lands Conservation Act and memoranda of understanding between the federal and state governments [Table A8-6; Journal Notes, January 30, 2013]. Democratic rule of law is an important guiding principle for agency managers (Mahoney et al. 2008: 9). Laws and regulations direct agencies in the United States to allocate fish and wildlife for harvest and other uses, and all citizens can equally participate in fish and wildlife management. An agency manager stated, 'It's simple; the law says we must protect the resource and provide opportunities for subsistence uses' (Journal Notes, January 30, 2013).

For the Yup'ik, there are appropriate ways to collaborate and work together. Subsistence harvesters expressed that knowledge and information are to be shared with everyone, not withheld [Table A2-5; 2-6; 2-7; 2-9]. Yup'ik elders have said it was the same as being a 'thief' to not share one's knowledge with others ... 'we must share our knowledge' (Journal Notes, January 14, 2013). Conversely, managers explained it is considered professional in agency culture to withhold some information during public meetings because speaking freely and openly about the issues may have unexpected consequences or negative repercussions. An agency manager explained: 
The reason that happens is because no one wants to see a free association of decision making between the managers going on in front of them. No one really wants to see my boss arguing with her boss or my boss arguing with the federal government or the federal government arguing with their boss. I mean ... that's unprofessional and should be done at some other level ... At some point you ... have to be allowed to decide and ... not in every case are they going to want to talk about it all in public ... because somebody might want to be candid, and that candor might not be ... their position ... What if I stood up in a meeting and said, well I think that's perfectly reasonable idea, and I think we should go ahead and do that and the ... [agency] is thinking well, we can't do that because law prohibits us from doing that, and it would really have been better for me to bring that concern up in private ... Some of the people in the working group appreciate that and some of them don't [Table A8-3]. Agency culture dictates that communications occur through proper channels via chain of command and supervisory approval. Information often is distributed on a need to know basis in agency settings. This atmosphere serves well to protect the interests of the agency but limits sharing information and knowledge with agency employees and partners.

In Yup'ik culture, one is expected to share and work together [Table A2]. Although some agency managers may be excellent relationship builders, there are substantial differences between collectivistic Yup'ik and individualistic Euro-American peoples regarding their approaches to problem solving, collaboration, and management and what success looks like in these endeavors [Table A8; Table A9]. Nearly every activity Yup'ik people conduct from birth to passing is approached with the help and guidance of others. The activities connected to hunting, collecting wood, berry picking, fishing, cutting fish, taking steam baths, and drying 
foods are collective activities. Because life's tasks are collectively, not individually, conducted in the Yup'ik world, effective negotiations, and collaborations with Yup'ik people require culturally appropriate approaches to promote togetherness, consensus, and sharing.

Yup'ik people understand and refer to meaningful people as 'real' people. The term real is not only used to identify a Yup'ik person. It is also used to define a set of characteristics someone or something possesses which makes that person or nonhuman being ideal and true in the Yup'ik context. For example, the nunapik, or the real land, refers to the tundra, the Delta, and the Yup'ik people's homeland. Pointing towards the tundra and the rivers during snow machine rides, our Yup'ik counterparts said, 'this is real Alaska.' A real person is defined as a person who engages with the real land and other real people to work towards betterment of their communities [Table A5]. Through their acts of involvement and positive contributions in their communities, they are afforded great respect from others. How the Yup'ik people interpret a real person has direct implications for how they perceive their involvement in collaborative management.

For the Yup'ik, knowledge is acquired through listening, observing, and most importantly, doing [Table A1]. When agency managers are perceived to lack experiential knowledge on the subject matter, subsistence harvesters question their capacity to be effective decision makers [Table A9-10; 20-4].

Decisions ... made from DC handed down to these management heads ... [is] a dangerous system for me. I mean with the stroke of a pen they'd easily wipe out my cultural, my traditional ... spiritual ties to the resource [Table A19-11]. Subsistence harvesters often shared that agency managers and decision makers do not know and understand Yup'ik culture and life in the Delta [Table A9-14; Table A18]. Conversely, one 
agency manager said that subsistence harvesters 'need to do their homework ... and understand some of the technical concepts that we're talking about' if they are to be effective managers [Table A13-2].

\section{Conclusion}

We co-constructed an understanding of the socio-cultural meanings that encompass collaborative management in the Yup'ik homeland. Qualitative interpretation is complex, and a thick description may often be elusive (Geertz, 1973). Ethnographic immersion in a place and culture does not guarantee perfect understanding or co-construction of meaning. However, based on our fieldwork and hermeneutic analysis, we confidently conclude that the collaborators in this case lack an understanding of each other's worldviews, cultural values, and desired outcomes of management. This lack of understanding is the most important factor affecting meaningful collaboration.

Although outside our purpose, we have realized that differences between Yup'ik language and English are closely related to the misunderstandings and divergent worldviews we have observed. There is an intimate relationship between a people's language and their view of the world (Moerman, 1988). 'Whatever we come to understand about being' in the world 'is always through the medium of language'; simply stated, language is the means to understanding (Gadamer, 1989; Lawn, 2006: 82-83). This is why the dimension, 'How we talk', in level one of Figure 4 is so important for understanding collaborative management. Since 'How we talk' is largely a nonvisible part of culture, agency managers and their Yup'ik partners must spend more time talking with and listening to each other. 'Linguistic meaning is a product of human dialogical interaction' (Gadamer, 1989; Lawn, 2006: 84). 
Managers and their Yup'ik partners must look beyond the visible outcomes of collaboration to achieve a more holistic and practical means of management. The decline in applications to serve on advisory boards is merely the tip of the iceberg. Deep below the waterline, several cultural drivers influence more observable challenges and unsatisfactory outcomes (Brooks and Bartley, 2016). How we perceive our world and our relationship to it, and how we live in our world greatly influence our approaches to problem solving and natural resources management. These partners must continually work towards a better understanding of their differences through better and more frequent social interactions.

The horizons of the partners must be brought into contact time and time again to allow a process of fusion to happen 'instead of one obliterating the other' (Gadamer, 1989; Lawn, 2006: 66). People learn the principles and ideals of culture and society through social interaction (Moerman, 1988). To increase and improve interactions, collaboration must not remain solely focused on the business at hand. Meetings and other interactions, both formal and informal, must include time for a variety of activities and events in remote communities and on the land, so people can talk, get to know one another, share experiences, hear stories, and develop common understandings. A fusion of horizons requires considerable time and continuous dialog because understanding continually changes as the world changes. Their collaborations will never be finished; the "fusion of horizons is ultimately an aspiration; it never can be fully achieved or finally completed' (Lawn, 2006: 66).

\section{Disclosure}

The authors declare no conflicts of interest. The authors alone are responsible for the content and writing of the paper. 


\section{Funding}

The authors disclosed receipt of the following financial support for the research, authorship, and/or publication of this article: This work was supported by the United States Fish and Wildlife Service, Office of Subsistence Management [cooperative agreement number F13AC00052] awarded through the Northwest and Alaska Cooperative Ecosystem Studies Unit.

\section{Ethics approval}

Ethical approval for this research with human subjects was granted by the University of Alaska Anchorage on September 19, 2012, Institutional Review Board Approval Number 360982-3.

\section{References}

Allen GM and Gould EM (1986) Complexity, wickedness, and public forests. Journal of Forestry 84: 20-23.

Altman I and Rogoff B (1987) Worldviews and psychology: trait, interactional, organismic, and transactional perspectives. In: Stokols D and Altman I (eds) Handbook of Environmental Psychology. New York: Wiley, pp. 1-40.

Arnold SJ and Fischer E (1994) Hermeneutics and consumer research. Journal of Consumer Research 21: 55-70.

Barker JH (1993) Always Getting Ready Upterrlainarluta: Yup'ik Eskimo Subsistence in Southwest Alaska. Seattle, WA: University of Washington Press.

Bartley KA (2012/2013) Field Journal Notes. Anchorage and Bethel, AK: Bartley. Bartley KA (2014) “They Don't Know How We Live”: Understanding Collaborative Management in the Delta. Master Thesis, University of Alaska Anchorage. 
Bartley KA, Brooks JJ and Boraas, AS (2014) Understanding and Improving Collaborative Management of Fish and Wildlife in Western Alaska. Soldotna, AK: Kenai Peninsula College.

Brooks JJ (2003) Claimed Identities, Personal Projects, and Relationship to Place: A Hermeneutic Interpretation of the Backcountry/Wilderness Experience at Rocky Mountain National Park. Dissertation, Colorado State University.

Brooks JJ and Champ PA (2006) Understanding the wicked nature of "unmanaged recreation" in Colorado’s Front Range. Environmental Management 38: 784-798.

Brooks JJ and Bartley KA (2016) What is a meaningful role? accounting for culture in fish and wildlife management in rural Alaska. Human Ecology 44: 517-531.

Brooks JJ, Wallace GN and Williams DR (2006) Place as relationship partner: an alternative metaphor for understanding the quality of visitor experience in a backcountry setting. Leisure Sciences 28: 331-349.

Carr WA (2010) The Faithful Skeptics: Conservative Christian Religious Beliefs and Perceptions of Climate Change. Master Thesis, University of Montana.

Freeman M (2006) Nurturing dialogic hermeneutics and the deliberative capacities of communities in focus groups. Qualitative Inquiry 12: 81-95.

Gadamer HG (1994) Forward. In: Grondin J (ed) Introduction to Philosophical Hermeneutics. New Haven, CT: Yale University Press.

Gadamer HG (1989) Truth and Method. (2 $2^{\text {nd }}$ ed.). New York: Crossroad.

Geertz C (1973) The Interpretation of Cultures: Selected Essays by Clifford Geertz. New York: Basic Books. 
Geertz C (1983) Local Knowledge: Further Essays in Interpretive Anthropology. New York: Basic Books.

Grondin J (1994) Introduction to Philosophical Hermeneutics. New Haven, CT: Yale University Press.

Hall ET (1976) Beyond Culture. Garden City, NJ: Anchor.

Heckman S (1984) Action as text: Gadamer's hermeneutics and the social scientific analysis of action. Journal for the Theory of Social Behavior 14: 333-354.

Hirschman EC (1986) Humanistic inquiry in marketing research: philosophy, method, and criteria. Journal of Marketing Research 23: 237-249.

Kvale S (1983) The qualitative research interview: a phenomenological and a hermeneutical mode of understanding. Journal of Phenomenological Psychology 14: 171-196.

Lawn C (2006) Gadamer: A Guide for the Perplexed. London: Continuum.

Mahoney SP, Geist V, Organ J et al. (2008) The North American Model of Wildlife Conservation: enduring achievement and legacy. In: Nobile J and Duda MD (eds) Strengthening America's Hunting Heritage and Wildlife Conservation in the 21st Century: Challenges and Opportunities. Washington, DC: Sporting Conservation Council, U.S. Department of Agriculture, and U.S. Department of the Interior, pp. 7-24. Mishler EG (1990) Validation in inquiry-guided research: the role of exemplars in narrative studies. Harvard Educational Review 60: 415-442.

Moerman M (1988) Talking culture: ethnography and conversation analysis. Philadelphia: University of Pennsylvania Press.

Nicholson G (1984) Seeing and Reading. Atlantic Highlands, NJ: Humanities Press. 
Olson DR (1986) Mining the human sciences: some relations between hermeneutics and epistemology. Interchange 17: 159-171.

Packer MJ and Addison RB (1989) Entering the Circle: Hermeneutic Investigation in Psychology. New York: State University Press.

Patterson ME and Williams DR (1998) Paradigms and problems: the practice of social science in natural resource management. Society and Natural Resources 11: 279-295.

Patterson ME and Williams DR (2002) Collecting and Analyzing Qualitative Data: Hermeneutic Principles, Methods, and Case Examples. Champaign, IL: Sagamore.

Patterson ME and Williams DR (2005) Maintaining research traditions on place: diversity of thought and scientific progress. Journal of Environmental Psychology 25: 361-380.

Patterson ME, Watson AE, Williams DR et al. (1998) An hermeneutic approach to studying the nature of wilderness experiences. Journal of Leisure Research 30: 423-452.

Russell RL (1988) A critical interpretation of Packer's 'Hermeneutic inquiry in the study of human conduct.' American Psychologist 43(2): 130-131.

Stewart J (1983) Interpretive listening: an alternative to empathy. Communication Education 32: 379-391.

Tesch R (1990) Qualitative Research Analysis Types and Software Tools. New York: Routledge Falmer.

Thompson CJ, Pollio HR and Locander WB (1994) The spoken and the unspoken: a hermeneutic approach to understanding the cultural veiwpoints that underlie consumers' expressed meanings. Journal of Consumer Research 21: 432-452.

Tufford L and Newman P (2012) Bracketing in qualitative research. Qualitative Social Work 11: 80-96. 
Turner dS (2003) Horizons revealed: from methodology to method. International Journal of Qualitative Methods 2: 1-17.

Wertz FJ (1983) From everyday to psychological description: analyzing the moments of a qualitative data analysis. Journal of Phenomenological Psychology 14: 197-241. 
Figure 1. A priori model based on the iceberg model of culture was adapted for the initial organizing system (Bartley, 2014; Bartley et al., 2014; Hall, 1976).

Figure 2. Interim organizing system at the time of the fourth synopses iteration (Bartley, 2014; Bartley et al., 2014).

Figure 3. A process for understanding meaning (Bartley, 2014; Bartley et al., 2014; Brooks and Bartley, 2014).

Figure 4. The final organizing system is the product of the interpretation and illustrates a meaningful understanding of collaborative management in western Alaska (Bartley, 2014). 